\title{
Cycloastragenol and Astragaloside IV activate telomerase and protect nucleus pulposus cells against high glucose-induced senescence and apoptosis
}

\author{
HAOFENG HONG ${ }^{1,2 *}$, JIAN XIAO ${ }^{1,2^{*}}$, QUANQUAN GUO ${ }^{1}$, JINHUI DU ${ }^{1}$, \\ ZHICHEN JIANG ${ }^{1}$, SISI LU ${ }^{1}$, HONGYUAN ZHANG ${ }^{1}$, \\ XIAOLEI ZHANG ${ }^{1-3}$ and XIANGYANG WANG ${ }^{1,2}$
}

\begin{abstract}
${ }^{1}$ Department of Orthopedics, The Second Affiliated Hospital and Yuying Children's Hospital of Wenzhou Medical University, Second Medical School of Wenzhou Medical University; ${ }^{2}$ Zhejiang Provincial Key Laboratory of Orthopedics, Wenzhou, Zhejiang 325027; ${ }^{3}$ Chinese Orthopedic Regenerative Medicine Society, Hangzhou, Zhejiang 310000, P.R. China
\end{abstract}

Received February 26, 2021; Accepted August 2, 2021

DOI: $10.3892 / \mathrm{etm} .2021 .10761$

\begin{abstract}
In diabetes-induced intervertebral disc degeneration (Db-IVDD), senescence and apoptosis of nucleus pulposus cells (NPCs) are major contributing factors. Telomere attrition and telomerase downregulation are some of the main reasons for senescence and eventual apoptosis. The derivatives of the Chinese herb Astragalus membranaceus, Cycloastragenol (CAG) and Astragaloside IV (AG-IV), are reportedly effective telomerase activators against telomere shortening; however, their effect in Db-IVDD have not been explored. The present study simultaneously investigated the regulation of these derivatives on senescence, apoptosis, telomeres and telomerase a model of high-glucose (HG)-induced stress using rat primary NPCs. The NPCs were stimulated with HG $(50 \mathrm{mM})$ to evoke HG-induced stress, and the effects of CAG and AG-IV were observed on: i) The expression level of senescence marker p16; ii) $\beta$-Gal staining; iii) the expression levels of apoptosis markers cleaved-caspase 3 (c-C3), BAX and $\mathrm{Bcl}-2$; iv) telomerase activation with telomerase reverse transcriptase (TERT) mRNA and protein expression, while
\end{abstract}

Correspondence to: Professor Xiangyang Wang, Department of Orthopedics, The Second Affiliated Hospital and Yuying Children's Hospital of Wenzhou Medical University, Second Medical School of Wenzhou Medical University, 109 Xueyuan Xi Road, Wenzhou, Zhejiang 325027, P.R. China

E-mail: xiangyangwang@wmu.edu.cn

Professor Xiaolei Zhang, Zhejiang Provincial Key Laboratory of Orthopedics, 109 Xue Yuan Xi Road, Wenzhou, Zhejiang 325027, P.R. China

E-mail: zhangxiaolei@wmu.edu.cn

*Contributed equally

Key words: cycloastragenol, astragaloside IV, intervertebral disc degeneration, apoptosis, senescence, telomere, telomerase telomere length was measured with reverse transcription-quantitative PCR. Cell proliferation was determined using the Cell Counting Kit-8 assay. Results demonstrated an upregulation in the expression levels of p16, c-C3 and BAX, and increased $\beta$-Gal staining; while the expression level of Bcl-2 was downregulated in a concentration-dependent manner. Pre-treatment of the NPCs with CAG and AG-IV downregulated the protein expression levels of $\mathrm{p} 16, \mathrm{c}-\mathrm{C} 3$ and $\mathrm{BAX}$, and decreased the percentage of $\beta$-Gal and FITC staining; while upregulating the Bcl-2 expression. These effects protected the cells from HG stress-induced senescence and apoptosis. HG also downregulated the expression profile of TERT and shortened the telomere length in a glucose concentration-dependent manner. While pretreatment with CAG and AG-IV upregulated TERT expression and ameliorated the telomere attrition. CAG and AG-IV also increased cell proliferation and improved cell morphology in HG conditions. Overall, these findings indicated that CAG and AG-IV suppressed HG stress-induced senescence and apoptosis, in addition to enhancing telomerase activation and lengthening of the Telomere. Therefore, CAG and AG-IV prolonged the replicative capability and longevity of the NPCs and they have the potential to be therapeutic agents in Db-IVDD.

\section{Introduction}

Lower back pain affects $80-85 \%$ of adults at a certain period during their lifetime $(1,2)$. Intervertebral disc degeneration (IVDD) is generally considered to be the main factor contributing to lower back pain (2). The intervertebral disc (IVD) is composed of annulus fibrosus, nucleus pulposus (NP) and cartilaginous endplates. NP is the most hydrated proteoglycan region of the IVD, comprising extracellular matrix and nucleus pulposus cells (NPCs). These enable the NP to maintain osmotic pressure and therefore to withstand compressive forces of the IVD. During degeneration, there are alterations in collagen proportions, the relative composition of proteoglycans and a greater water loss from the NP, resulting in loss of the hydrostatic properties of the disk (2). 
Several studies suggest that apoptosis and senescence of NPCs are associated with disc degeneration $(3,4)$. Diabetes has been revealed to be a clinical risk factor of IVDD $(3,5)$. Studies have shown that high-glucose (HG) concentrations may induce disc cell apoptosis and senescence, as well as abnormal matrix metabolism (4-7).

Telomere attrition is associated with this phenomenon; when the telomere is shortened, it results in senescence and ultimately apoptosis, which further deteriorates the condition of the cells and the IVD (8). Studies have indicated that diabetes accelerates telomere attrition in type 2 diabetic patients $(9,10)$. Studies have also demonstrated that telomere attrition and lower telomerase expression is involved in diverse types of diseases, including IVDD. Therefore, telomerase is considered a potential therapeutic target for these diseases $(8,9)$. Telomerase reverse transcriptase (TERT), together with the telomerase RNA component (TERC), is the most important unit of the telomerase complex, though TERT is able to perform its function without the presence of TERC (11). TERT activation may result in a protective effect against degeneration and increase the resistance of cells to glucose-mediated stress (12). Lower expression levels of TERT have been implicated in various disorders, including degenerative diseases (13). A study by Graham et al (14) revealed that TERT significantly suppresses p16 expression. A study by Chung et al (12) on NPCs and gene therapy considered telomerase to be a therapeutic target. However, to the best of our knowledge, its role in HG-IVDD is unknown.

Extracts from Astragalus roots are recognized as traditional medicines and foods (15). Cycloastragenol (CAG) is a bioactive molecule isolated from various species in the Astragalus genus, whichare used as a dietary ingredients $(16,17)$. Astragalosides are chemical compounds isolated from the dried root of the fundamental Chinese herb Astragalus membranaceus. Astragaloside IV (AG-IV) has numerous pharmaceutical properties, such as anti-inflammation, anti-insulin resistance, antitumor and neuroprotection (18-21). CAG, AG-IV and other associated molecules have been identified as small-molecule telomerase activators (16). Previous studies have demonstrated that $\mathrm{CAG}$ and $\mathrm{AG}-\mathrm{IV}$ are able to alleviate and reverse a number of degenerative diseases, such as metabolic syndrome, arthritis and age-related macular degeneration, by activating telomerase $(18,19,22)$. However, the effects of both of these drugs on HG-IVDD are unknown. Therefore, the present study hypothesized that they may postpone the progression of HG-IVDD by upregulating TERT.

The present study demonstrated the expression profile of TERT in NPCs and that CAG and AG-IV can activate TERT, indicating its therapeutic potential in HG IVDD. To the best of our knowledge, this is the first report to describe the link between TERT and HG-induced IVDD, and to also introduce CAG and AG-IV as pharmacological agonists of TERT in the treatment of IVDD.

\section{Materials and methods}

Ethics statement. The present study was carried out in accordance with the Guide for the Care and Use of Laboratory Animals of the National Institutes of Health (NIH Publications No. 8023, revised 1978). The animal protocol was approved by the Ethics Committee of Wenzhou Medical University (approval no. wydw2014-0129; Wenzhou, China).

Reagents and antibodies. CAG (CAS 84605-18-5; cat. no. ZL20170428) and Astragaloside IV (CAS 84687-43-4; cat. no. ZL20170415) were purchased from Nanjing Zelang Medical Technology Co., Ltd. with $\geq 98 \%$ purity. The monoclonal anti-p16 ${ }^{\mathrm{INK} 4 \mathrm{a} / \mathrm{CDKN} 2}$ antibody (cat. no. SAB5300498), D-glucose, T-hydro tert-butyl hydroperoxide (TBHP) and type II collagenase were from Sigma-Aldrich (Merck KGaA). Monoclonal anti-cleaved caspase 3 (c-C3) antibody (cat. no. 9664) was supplied by Cell Signaling Technology, Inc. Monoclonal anti-BAX antibody (cat. no. ab232479) was acquired from Abcam. Monoclonal anti-Bcl-2 antibody (cat. no. 625509) was obtained from R\&D Systems, Inc. Monoclonal anti- $\alpha$ tubulin antibody (cat. no. 66031-1-Ig) was obtained from ProteinTech Group, Inc. Polyclonal anti-TERT antibody (cat. no. ABE2075) was purchased from MilliporeSigma. Anti-rabbit and anti-mouse horseradish peroxidase-labeled secondary antibodies (cat. nos. BL003A and BL001A) were obtained from Biosharp Life Sciences. BCA kit, RIPA lysis buffer and phenylmethylsulfonyl fluoride (PMSF) were purchased from Beyotime Institute of Biotechnology. Femto Enhanced Chemi-Luminescence substrate and primers for PCR were purchased from Thermo Fisher Scientific, Inc. SYBR ${ }^{\circledR}$ Green system (cat. no. RR420L) for reverse transcription-quantitative PCR (RT-qPCR) was purchased from Takara Biotechnology Co., Ltd. DNeasy animal blood and tissue kit (cat. no. 69506) was purchased from Qiagen $\mathrm{GmbH}$. DMEM and FBS for cell culture were purchased from Gibco (Thermo Fisher Scientific, Inc.).

NPC isolation and cell culture. Gel-like tissues (nucleus pulposus) were collected from the tail intervertebral discs of 35 male Sprague-Dawley rats (age, 3-4 weeks; weight, 50-100 g), which were obtained from the Animal Center of the Chinese Academy of Sciences. Rats were housed individually at $23-25^{\circ} \mathrm{C}$ with a $40-50 \%$ humidity under a $12 \mathrm{~h}$ dark/light cycle with free access to standard chow. Before collecting tissues, the rats were anesthetized with $50 \mathrm{mg} / \mathrm{kg}$ nembutal. The NP tissues of the L1-L6 spinal column were collected in sterile environment and then digested in $0.2 \%$ type II collagenase for $\sim 4 \mathrm{~h}$ at $37^{\circ} \mathrm{C}$. Sprague-Dawley rats were then euthanized with the $200 \mathrm{mg} / \mathrm{kg}$ Nembutal (23). After washing with PBS twice, the digested tissues were transferred to DMEM $1 \mathrm{~g} / \mathrm{l}$ $(5.5 \mathrm{mM})$ with $15 \% \mathrm{FBS}$ and $1 \%$ antibiotics $(100 \mathrm{U} / \mathrm{ml}$ penicillin and $100 \mu \mathrm{g} / \mathrm{ml}$ streptomycin) and placed in an incubator of $5 \% \mathrm{CO}_{2}$ at $37^{\circ} \mathrm{C}$. When cells reached $80-90 \%$ confluence, the cells were passaged following trypsinization with $0.25 \%$ Trypsin-EDTA, and cultured in $10-\mathrm{cm}$ culture plates at a density of $2 \times 10^{5}$ cells $/ \mathrm{ml}$. The first three passages cells were used in the experiments.

Treatment protocol of cell culture. D-glucose was added to the DMEM (low glucose) and then filtered through sterile 0.45-mm PVDF Membrane filter (Merck KGaA) and a stock solution of $500 \mathrm{mM}$ glucose concentration was obtained. Then the stock solution was diluted in complete culture media to obtain the desired concentrations of glucose $(5.5,12.5$, 
50,100 and $200 \mathrm{mM}$ ). When $50-70 \%$ confluence was. reached, NPCs were treated with different doses of glucose at $37^{\circ} \mathrm{C}$ for varying amounts of time $(24,48,72$ or $96 \mathrm{~h})$.

CAG and AG-IV were dissolved in dimethyl sulfoxide (DMSO) at concentrations of $500 \mathrm{mM}$, and then appropriately diluted with complete culture medium (final DMSO concentration $<1 \%$ ). All the relevant groups were pretreated with different drug concentrations $(1,3,5$ and $10 \mathrm{mM})$ and then with HG $(50 \mathrm{mM})$. All the experiments were performed in triplicate.

Cell viability assay. NPCs were seeded in 96-well plates $\left(5,000\right.$ cell/well) and incubated at $37^{\circ} \mathrm{C}$ for $72 \mathrm{~h}$. Subsequently, the NPCs were treated with DMEM (15\% FBS) in increasing concentrations and times of glucose, or with increasing CAG and AG-IV concentrations $(0.01,0.1,0.5,1,3,5,10,50$ and $100 \mu \mathrm{M})$ for different time periods $(24,48,72$ and $96 \mathrm{~h})$. After washing the cells with PBS, $100 \mu 1$ of DMEM containing $10 \mu 1$ of Cell Counting Kit-8 (CCK-8; Beyotime Institute of Biotechnology) solution was added to each well according to the manufacturer's protocol. The plate was then incubated for $\sim 1 \mathrm{~h}$ at $37^{\circ} \mathrm{C}$. The optical density of the wells was measured at $450 \mathrm{~nm}$ using a microplate reader.

Western blotting. NPCs were lysed on ice-cold RIPA lysis buffer with $1 \mathrm{mM}$ PMSF. Protein concentrations of samples were measured using the BCA protein assay kit. Samples with equal amounts of protein $(40 \mu \mathrm{g})$ were then separated by $12-15 \%$ SDS-PAGE and transferred to a PVDF membrane (MilliporeSigma). Membranes were blocked with 5\% non-fat milk for $2 \mathrm{~h}$ at room temperature. The bands were probed with primary antibodies specific to p16 (1:500), c-C3 $(1: 1,000)$, $\operatorname{BAX}(1: 1,000), \operatorname{Bcl}-2(1: 1,000), \alpha$-Tubulin $(1: 1,000)$ and TERT $(1: 1,000)$ overnight at $4{ }^{\circ} \mathrm{C}$, before being incubated with respective anti-rabbit $(1: 1,000)$ and anti-mouse $(1: 1,000)$ horseradish peroxidase-labeled secondary antibodies for $2 \mathrm{~h}$ at room temperature. Blots were visualized using ECL (Thermo Fisher Scientific, Inc.). The intensity of these bands were semi-quantified using Image Lab 3.0 software (Bio-Rad Laboratories, Inc.).

$R T-q P C R$ analysis. Total RNA was isolated from NPCs using TRIzol ${ }^{\circledR}$ reagent (Invitrogen; Thermo Fisher Scientific,Inc.), and $1 \mu \mathrm{g}$ of total RNA was used to synthesize cDNA. Quantitative PCR was performed using the $\mathrm{SYBR}^{\circledR}$ Green system (Takara Bio, Inc.). Amplification of cDNA samples was carried out on the CFX96 real-time PCR system (Bio-Rad Laboratories, Inc.). The reaction steps were as follows: $95^{\circ} \mathrm{C}$ for $3 \mathrm{~min}, 60^{\circ} \mathrm{C}$ for $45 \mathrm{sec}$ and for 39 cycles. At-last melt curve analysis: $65^{\circ} \mathrm{C}$ Then $95^{\circ} \mathrm{C}$ and $5^{\circ} \mathrm{C}$ for $5 \mathrm{sec}$ each. The relative quantification of the target gene was normalized to $\beta$-actin, and target gene was compared with the control sample using the $2^{-\Delta \Delta C q}$ method (24). The primers for TERT and $\beta$-actin are listed in Table I.

DNA was extracted using the DNeasy kit from Qiagen $\mathrm{GmbH}$. After the DNA was extracted from the NPCs in six-well plates at a seeding density of $2 \times 10^{5}$ cells $/ \mathrm{ml}$ following the manufacturer's protocols, then the same protocol and quantification of qPCR data were carried out as aforementioned. The primers of Telomere and 36B4 are listed in Table I.
Sa- $\beta$-gal staining. NPCs were seeded in 6-well plates for $72 \mathrm{~h}$ at a seeding density of $2 \times 10^{5}$ cells $/ \mathrm{ml}$, washed twice with PBS and fixed with $0.2 \%$ glutaraldehyde for $10 \mathrm{~min}$ at room temperature. Cells were subsequently stained with $\mathrm{X}$-gal staining solution overnight at $37^{\circ} \mathrm{C}$ at $\mathrm{pH}$ 6.0. The next day, images were captured by using an inverted Olympus IX71 light microscope (magnification, x200; Olympus Corporation) and the percentage of SA- $\beta$-gal-positive cells were quantified using Image Lab 3.0 software (Bio-Rad Laboratories, Inc.).

Flow cytometry. Apoptosis was detected using an Annexin-V apoptosis detection kit (Becton-Dickinson and Company) as described by the manufacturer's protocol. NPCs were seeded at a density of $2 \times 10^{5}$ cells $/ \mathrm{ml}$ in 6 -well plates and treated with different concentrations of glucose, CAG and AG-IV at $37^{\circ} \mathrm{C}$ for $72 \mathrm{~h}$. Subsequently, $\sim 10^{6}$ cells from each well were collected, washed and re-suspended in $100 \mu 1$ of binding buffer with $5 \mu \mathrm{l}$ of Annexin-V FITC and $5 \mu \mathrm{l}$ propidium iodide for $30 \mathrm{~min}$ in the dark at room temperature. Cells were analyzed using flow cytometry (BD Biosciences; Becton, Dickinson and Company). The total apoptosis rate (early stage apoptosis plus late stage apoptosis) of NPCs was calculated as the percentage of the ratio observed in the lower-right and the upper-right quadrants.

Statistical analysis. All the experiments were performed at least three times. Results were expressed as mean \pm standard deviation. Statistical analyses were performed using GraphPad Prism (version 7.0; GraphPad Software, Inc.). Data were analyzed by one-way analysis of variance (ANOVA) followed by the Dunnett's multiple tests for comparison between control and treatment groups. $\mathrm{P}<0.05$ was considered to indicate a statistically significant difference.

\section{Results}

$H G$ concentrations adversely affect the viability of NPCs. To investigate HG-induced cytotoxicity in the primary NPCs, they were treated with different concentrations of glucose for varying amounts of time. The cytotoxic effect of glucose on NPCs was determined at various concentrations of glucose $(5.5,12.5,25,50,100$ and $200 \mathrm{mM})$ for $24-96 \mathrm{~h}$ using a CCK-8 assay. As presented in Fig. 1, there were significant cytotoxic effects following HG treatment on the NPCs, especially at higher doses $(50,100$ and $200 \mathrm{mM}$ glucose for 24-96 h; $\mathrm{P}<0.05)$. While simulating the pathophysiological characteristics of the chronic course of diabetes, treatment for $72 \mathrm{~h}$ exhibited similar effects to treatment for $96 \mathrm{~h}$. Thus, treatment using $50 \mathrm{mM}$ glucose for $72 \mathrm{~h}$ was selected for subsequent experiments.

$H G$ concentrations have adverse effects on TERT expression and telomere length in NPCs. Fig. 2A presents western blotting of TERT protein expression levels in NPCs when treated with glucose at various concentrations $(5.5,12.5,25$, 50,100 and $200 \mathrm{mM}$ ) for $72 \mathrm{~h}$; the expression level of TERT notably decreased with higher concentrations of glucose. Fig. 2B demonstrated that TERT protein expression levels were significantly decreased at higher concentrations of glucose in a dose-dependent manner $(\mathrm{P}<0.05)$. 
Table I. Primer sequences for reverse transcription-quantitative PCR.

\begin{tabular}{lll}
\hline Gene & \multicolumn{1}{c}{ Forward primer $\left(5^{\prime}-3^{\prime}\right)$} & \multicolumn{1}{c}{ Reverse primer $\left(5^{\prime}-3^{\prime}\right)$} \\
\hline$\beta$-actin & CCGCGAGTACAACCTTCTTG & TGACCCATACCCACCATCAC \\
TERT & AGTGGTGAACTTCCCTGTGG & CAACCGCAAGACTGACAAGA \\
Telomere & GGTTTTGAGGGTGAGGGTGAGGG & TCCCGACTATCCCTATCCCTATCCC \\
$36 \mathrm{~B} 4$ & TGAGGGTGAGGGT & TATCCCTATCCCTA \\
& CTCACTCCATCATCAATGGATACAA & CAGCCAGTGGGAAGGTGTAGTCA
\end{tabular}

TERT, telomerase reverse transcriptase.

A

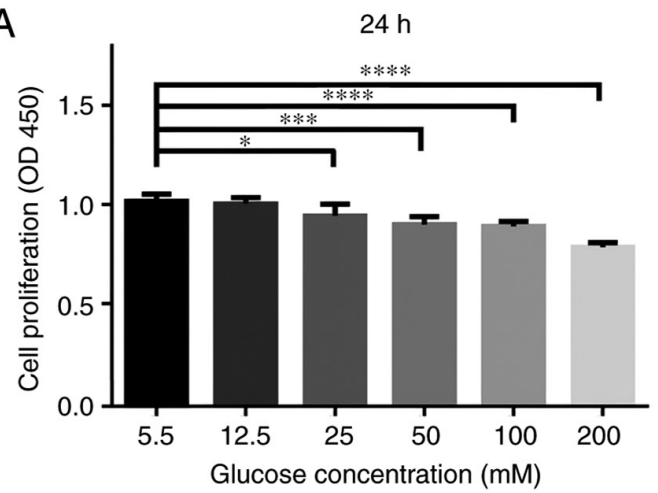

C

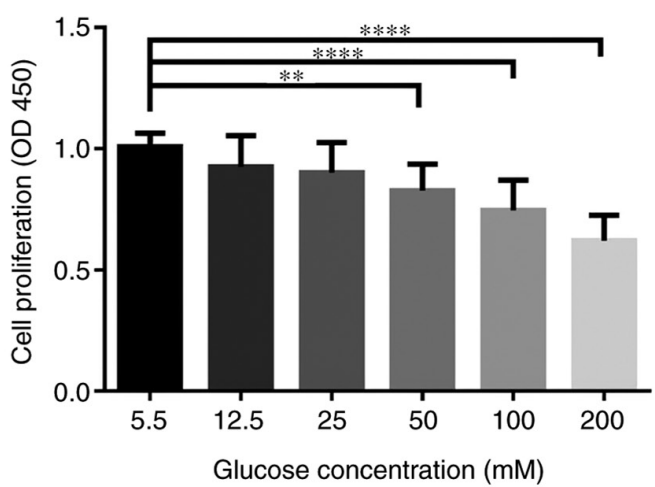

B

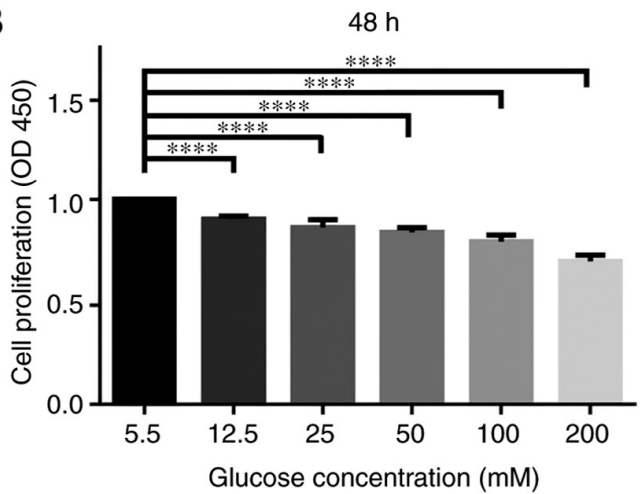

D

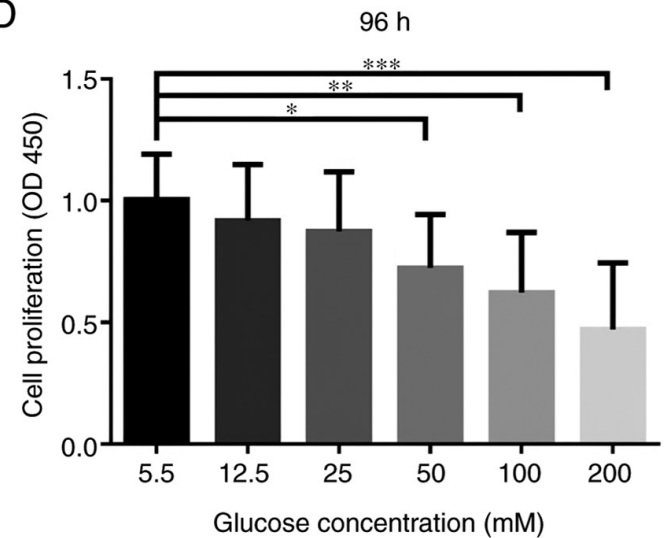

Figure 1 . HG concentrations adversely affects the cellular viability of rat NPCs. NPCs were treated with different concentrations of glucose $(5.5,12.5,25,50$, 100 and $200 \mathrm{mM}$ ) for varying durations $(24,48,72$ and $96 \mathrm{~h})$ in complete DMEM culture media. CCK- 8 results of NPCs treated with different concentrations of glucose for (A) $24 \mathrm{~h}$, (B) $48 \mathrm{~h}$, (C) $72 \mathrm{~h}$ and (D) for $96 \mathrm{~h}$. n=5/group. ${ }^{*} \mathrm{P}<0.05 ;{ }^{* *} \mathrm{P}<0.01 ;{ }^{* * * *} \mathrm{P}<0.001 ;{ }^{* * * *} \mathrm{P}<0.0001$ vs. 5.5 mM. NPCs, nucleus pulposus cells. HG, high glucose (50 mM); CCK-8, Cell Counting Kit-8; OD, optical density.

Meanwhile, as presented in Fig. 2C, the expression of mRNA TERT in RT-qPCR was also decreased in a dose-dependent manner $(\mathrm{P}<0.0001)$. In addition, as presented in Fig. 2D, the telomere length, detected using the qPCR method by Cawthon (25), also decreased in a dose-dependent manner $(\mathrm{P}<0.05)$. Telomere length was observed using qPCR, using the Cawthon method, which is the standard method to check for the telomere length. These results demonstrated that high levels of glucose inhibited the expression of TERT and shortened the telomere length.

$H G$ concentrations promote apoptosis and senescence of $N P C s$. Fig. 3A-D presents the expression levels of apoptosis-related proteins (c-C3, BAX and Bcl-2) in NPCs detected by western blotting after treatment with various concentrations of glucose $(5.5,12.5,25,50,100$ and $200 \mathrm{mM})$ for $72 \mathrm{~h}$. The expression levels of $\mathrm{c}-\mathrm{C} 3$ and BAX proteins were significantly increased in a glucose dose-dependent manner; while Bcl-2 expression was significantly decreased $(\mathrm{P}<0.05)$.

Moreover, as presented in Fig. $3 \mathrm{E}$ and $\mathrm{G}$, the percentage of apoptosis as detected by Annexin-V was significantly increased in a glucose dose-dependent manner $(\mathrm{P}<0.0001)$. The results of the western blotting in Fig. $3 \mathrm{H}$ and I also demonstrated that the expression level of p16 protein was increased in a dose-dependent manner $(\mathrm{P}<0.01)$. In addition, the $\beta$-Gal staining in Fig. 3F and $\mathrm{J}$ indicates a significantly higher percentage of positively stained cells in a glucose concentration-dependent manner $(\mathrm{P}<0.05)$ These results demonstrated 
A

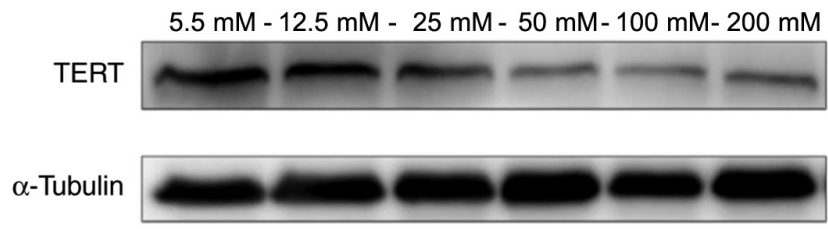

C

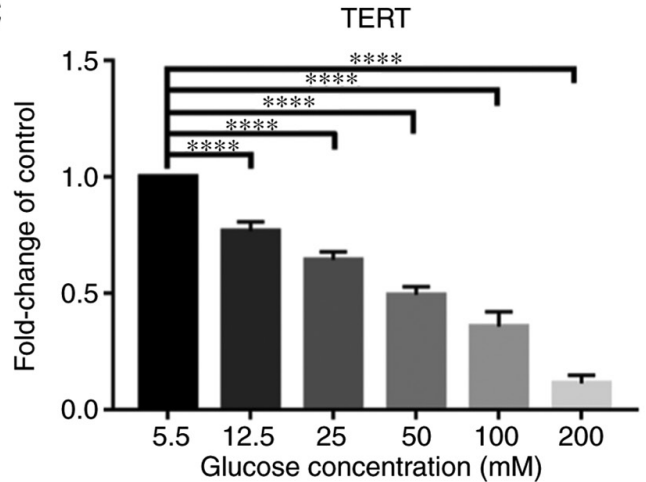

B

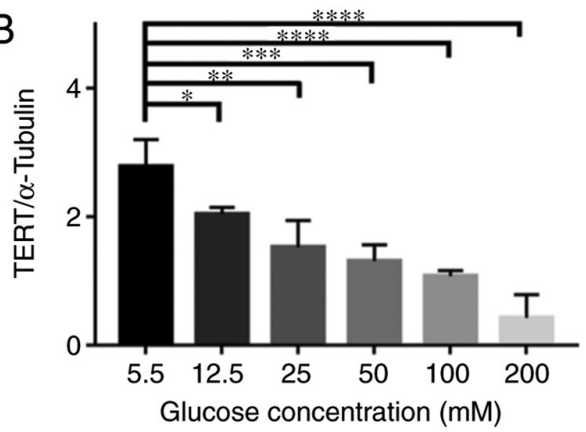

D

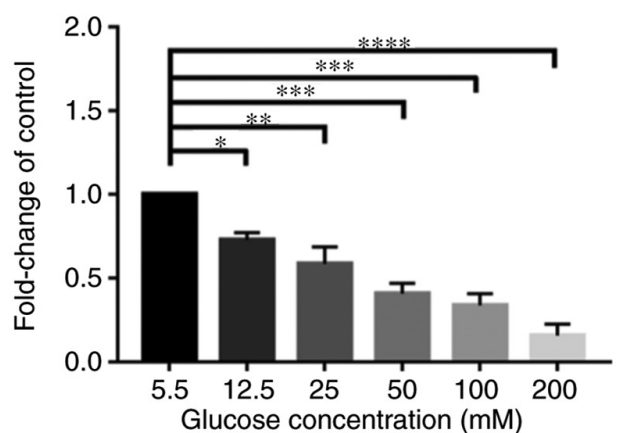

Figure 2. HG concentrations has significant effect on TERT expression and telomere length in NPCs. Protein expression levels of TERT in the LG group and the 12.5, 25, 50, 100 and $200 \mathrm{mM}$ glucose concentration groups were tested with (A) western blotting and (B) quantified. $\alpha$-Tubulin was used as the loading control and for band density normalization. (C) mRNA expression of TERT in NPCs treated with glucose was measured by RT-qPCR with $\beta$-Actin as the house-keeping gene for normalization. (D) Relative telomere length was assessed by using the qPCR method with the 36B4 being the single copy gene for normalization. ${ }^{*} \mathrm{P}<0.05 ;{ }^{* *} \mathrm{P}<0.01 ;{ }^{* * *} \mathrm{P}<0.001 ;{ }^{* * * *} \mathrm{P}<0.0001$ vs. $5.5 \mathrm{mM}$. HG, high glucose $(50 \mathrm{mM})$; NPCs, nucleus pulposus cells; TERT, telomerase reverse transcriptase; RT-qPCR, reverse transcription-quantitative PCR; TELO, telomere.

that high levels of glucose significantly promoted the cellular apoptosis and senescence of NPCs.

Cytotoxicity of CAG and AG-IV on NPCs. NPCs were treated with different doses of CAG and AG-IV and the cytotoxic effects of these drugs were determined at various concentrations $(0.01,0.1,0.5,1,3,5,10,50$ and $100 \mathrm{mM})$ for $24 \mathrm{~h}$ using the CCK-8 assay. As presented in Fig. 4A and B, there were significant cytotoxic effects at high doses $(50$ and $100 \mathrm{mM})$ of both drugs on the NPCs $(\mathrm{P}<0.05)$. For subsequent experiments, the concentrations of $1,3,5$ and $10 \mathrm{mM}$ for $24 \mathrm{~h}$ were selected as the experimental concentrations.

$C A G$ and $A G-I V$ improve cell morphology and viability in $H G$ conditions. NPCs seeded in 24-well plates were pretreated with CAG or AG-IV at different concentrations $(1,3,5$ or $10 \mathrm{mM})$ for $24 \mathrm{~h}$, and then serum starved for $24 \mathrm{~h}$ and treated with a $\mathrm{HG}$ concentration of $50 \mathrm{mM}$ for $72 \mathrm{~h}$. Compared with the low glucose (LG, $5.5 \mathrm{mM}$ ) group, the NPCs differed in size and shape (bigger cells) and the cell cytoplasm seemed coarse when treated with $\mathrm{HG}(50 \mathrm{mM})$. However, treatment with CAG or AG-IV could prevent this phenomenon at concentrations of 1, 3 and $5 \mathrm{mM}$ (Fig. 5A).

The cellular viability was determined after $72 \mathrm{~h}$ of $\mathrm{HG}$ treatment in pretreated NPCs using the CCK-8 assay. As presented in Fig. 5B, there is a significant difference between the untreated group (DMSO HG) and treated groups (CAG and AG-IV). After treating with $\mathrm{HG}$, the cell viability was decreased compared with the DMSO LG group $(\mathrm{P}<0.001)$; however, CAG and AG-IV demonstrated a significant protective effect against $\mathrm{HG}(\mathrm{P}<0.05$; Fig. 5B). These results demonstrated that CAG and AG-IV pretreatment resulted in improved morphology of the HG-treated NPCs and significantly increased their viability.

CAG and AG-IV increase TERT expression and telomere length of NPCs in HG conditions. NPs were pretreated with CAG or AG-IV at 1, 3, 5 and $10 \mathrm{mM}$ concentrations for $24 \mathrm{~h}$, serum-starved for $24 \mathrm{~h}$ and then treated with a HG concentration of $50 \mathrm{mM}$ for $72 \mathrm{~h}$. In Fig. 6A and B, western blotting demonstrated that TERT protein expression levels were significantly decreased in HG-only conditions compared with the LG group, but the expression recovered in CAG and AG-IV drug treatment groups $(\mathrm{P}<0.05)$.

Meanwhile, as presented in Fig. 6C, the mRNA expression of TERT in RT-qPCR was also markedly decreased in HG-only conditions compared with the LG group, but the difference was not statistically significant $(\mathrm{P}>0.05)$; however the expression levels significantly increased in drug treatment groups at 3 and $5 \mathrm{mM}$ concentrations $(\mathrm{P}<0.05)$. Moreover, Fig. 6D indicates that the telomere length detected using the qPCR method (25) was also markedly decreased in HG-only conditions compared with the LG group, but this result was not statistically significant. However, the telomere length significantly increased in drug treatment groups at 3 and $5 \mathrm{mM}$ concentrations compared with the HG-only group $(\mathrm{P}<0.05)$. Overall, compared with the HG group (DMSO HG), all other groups exhibited higher TERT protein and mRNA expression levels, and longer telomere length. 

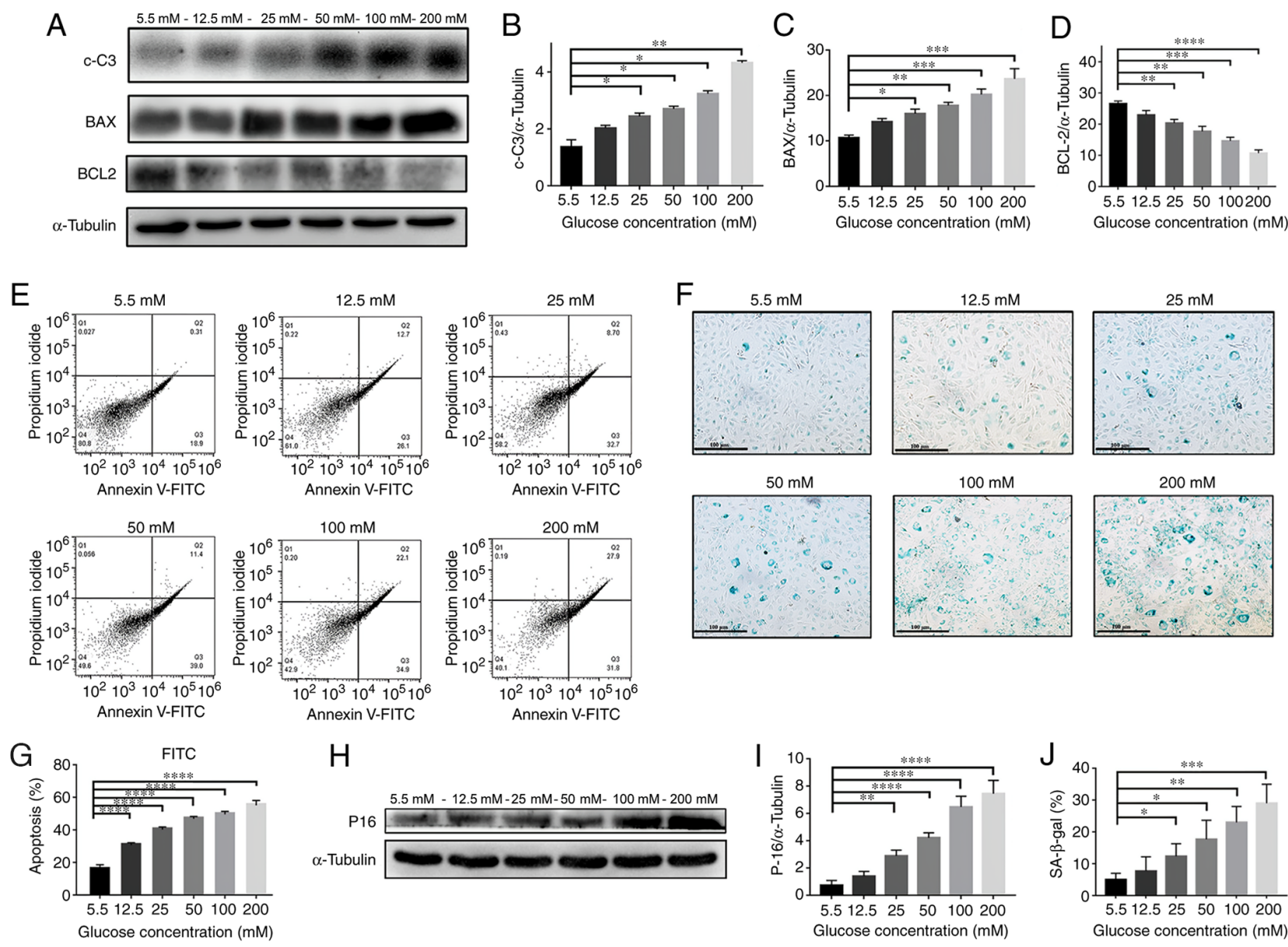

$\mathrm{H}$
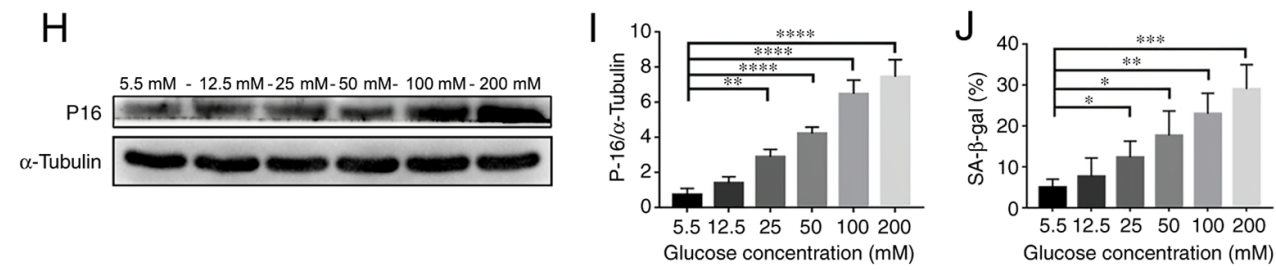

Figure 3. HG induces NPC apoptosis and senescence. (A) Western blotting results of protein content and quantification of (B) c-C3, (C) BAX and (D) BCL-2 in NPCs treated with different concentrations $(5.5,12.5,25,50,100$ and $200 \mathrm{mM}$ ) of glucose for $72 \mathrm{~h}$. (E) Flow cytometry plots and (G) quantified results of NPCs treated with different concentrations of glucose for $72 \mathrm{~h}$. (H) p16 western blotting results and (I) quantification of protein contents of NPCs treated with different concentrations of glucose for $72 \mathrm{~h}$. (F) SA- $\beta$-gal staining assay was performed and (J) quantified on NPCs treated with different concentrations of glucose for $72 \mathrm{~h}$ (magnification, $\mathrm{x} 100$; scale bar, $100 \mu \mathrm{m}$ ). ${ }^{*} \mathrm{P}<0.05 ;{ }^{* *} \mathrm{P}<0.01 ;{ }^{* * *} \mathrm{P}<0.001 ;{ }^{* * * * *} \mathrm{P}<0.0001$ vs. $5.5 \mathrm{mM}$. NPCs, nucleus pulposus cells; HG, high-glucose $(50 \mathrm{mM})$; LG, low-glucose $(5.5 \mathrm{mM})$; c-C3, cleaved caspase 3.

A

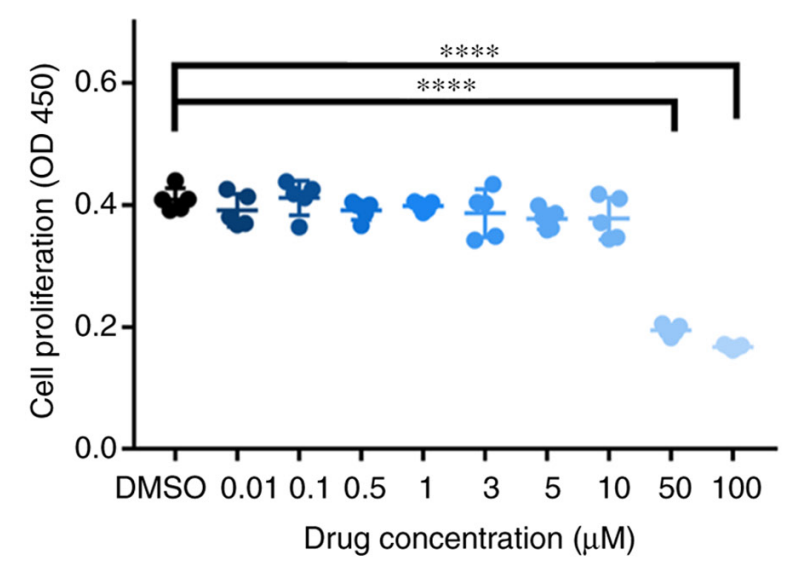

B

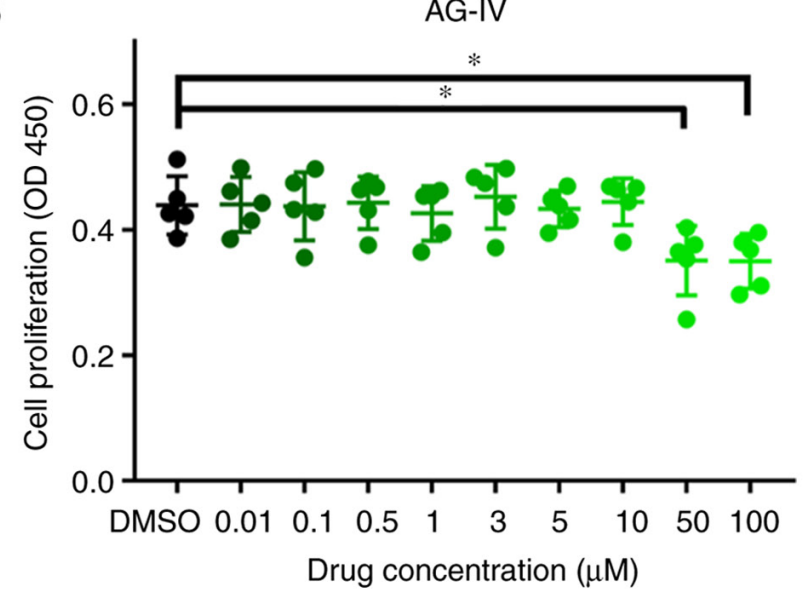

Figure 4. Effects of CAG and AG-IV on the cell viability of NPCs. Cytotoxic effect of (A) CAG and (B) AG-IV on NPCs was determined at various concentrations for $24 \mathrm{~h}$ using a Cell Counting Kit-8 assay. $\mathrm{n}=4{ }^{*}{ }^{*} \mathrm{P}<0.05{ }^{*}{ }^{* * * *} \mathrm{P}<0.0001$ vs. control. CAG, cycloastragenol; AG-IV, Astragaloside IV; NPCs, nucleus pulposus cells; OD, optical density.

These results demonstrated that TERT expression and telomere length both increased in NPCs undergoing HG-induced stress, following treatment with CAG and AG-IV.
$C A G$ and $A G-I V$ suppress apoptosis and senescence in $H G$ conditions. The NPCs were pretreated with CAG or AG-IV at $1,3,5$ and $10 \mathrm{mM}$ concentrations for $24 \mathrm{~h}$, serum-starved for 
A
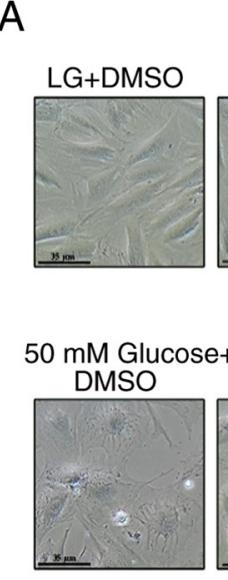

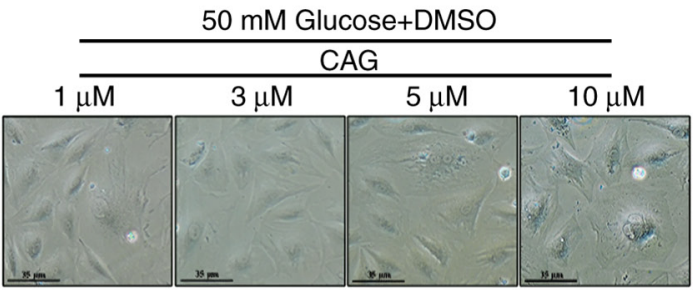

$50 \mathrm{mM}$ Glucose+DMSO

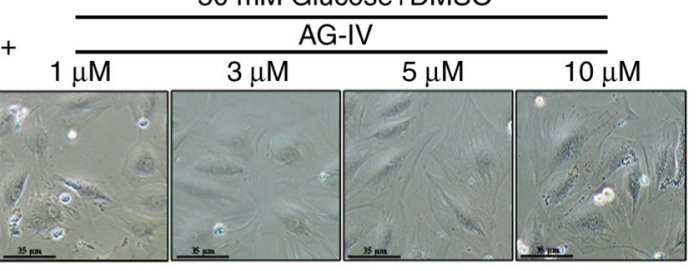

$\mathrm{B}$

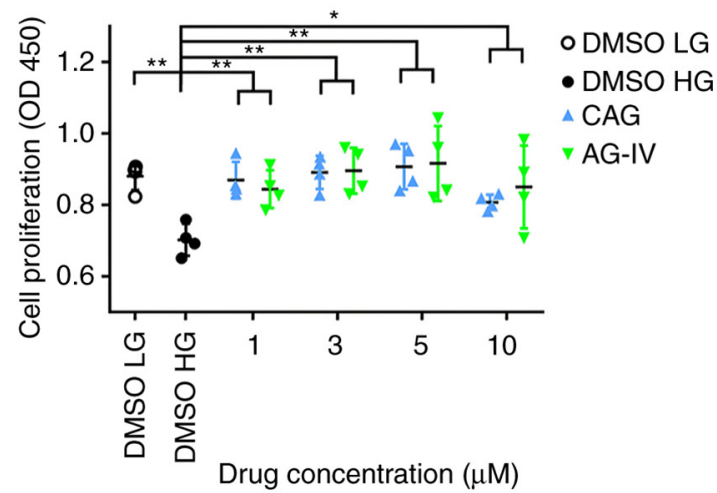

Figure 5. CAG and AG-IV improve cell viability and in HG conditions. (A) Morphological results of cells stimulated by HG and pretreated with CAG or AG-IV. Cells were stimulated by $50 \mathrm{mM}$ glucose for $72 \mathrm{~h}$. (magnification, x100; scale bar, $35 \mu \mathrm{m}$ ). HG changed the morphology of NPCs, while CAG and AG-IV treatment rescued them. (B) Cellular viability as depicted by Cell Counting Kit-8 indicated that CAG and AG-IV significantly improved cellular viability in of NPCs in HG conditions. $\mathrm{n}=4 .{ }^{*} \mathrm{P}<0.05 ;{ }^{* *} \mathrm{P}<0.01$ vs. control. CAG, cycloastragenol; AG-IV, Astragaloside IV; HG, high glucose (50 $\left.\mu \mathrm{M}\right)$; LG, low glucose (5.5 mM); NPCs, nucleus pulposus cells; OD, optical density.

A

DLG $-\mathrm{DHG}-1 \frac{\mathrm{CAG}}{1 \mu \mathrm{M}-3 \mu \mathrm{M}-5 \mu \mathrm{M}-10 \mu \mathrm{M}-1} \frac{\mathrm{AG}-\mathrm{IV}}{\mu \mathrm{M}-3 \mu \mathrm{M}-5 \mu \mathrm{M}-10 \mu \mathrm{M}}$ TERT

$\alpha$-Tubulin

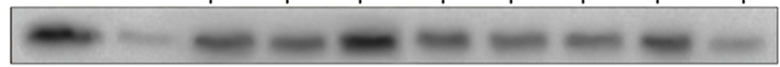

C

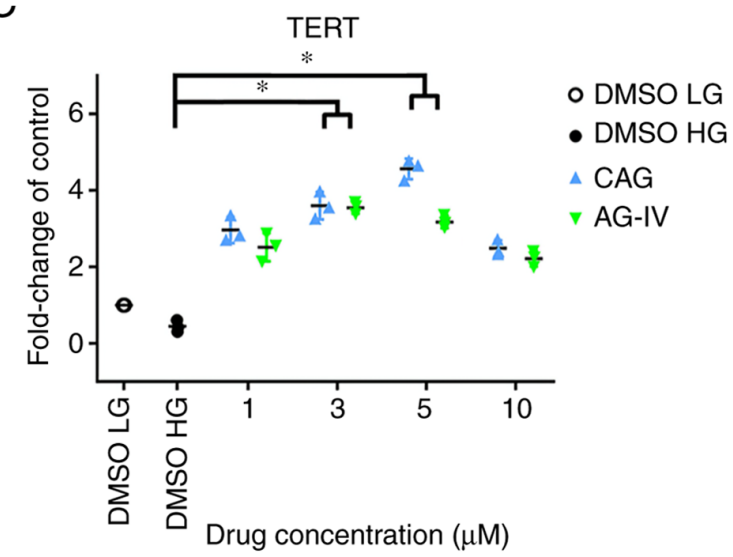

B

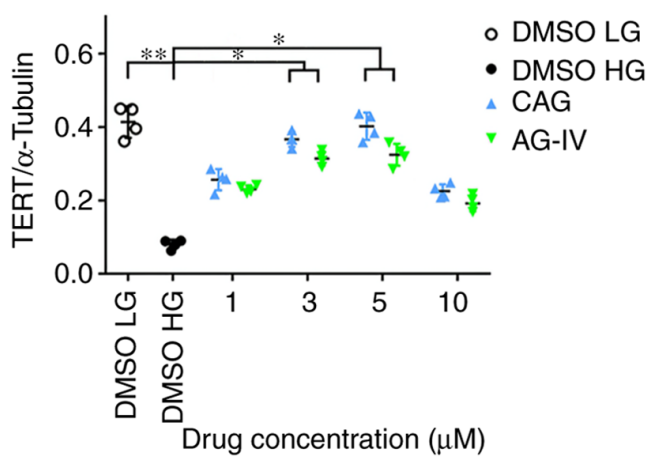

$\mathrm{D}$

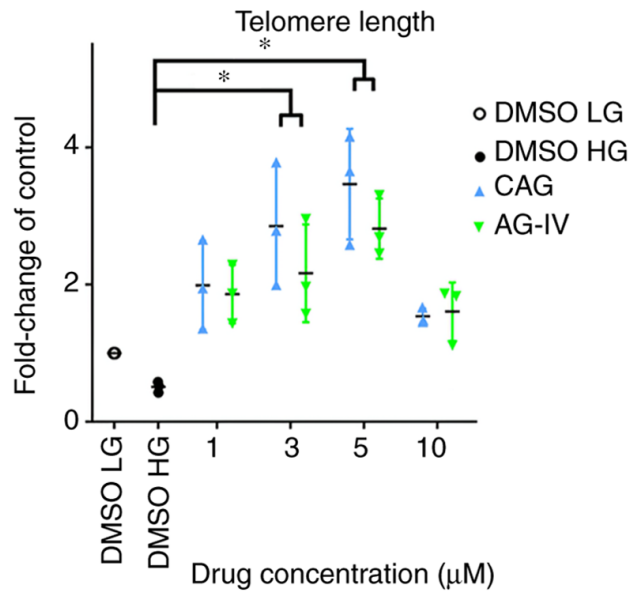

Figure 6. CAG and AG-IV increase TERT expression and telomere length of NPCs in HG conditions. (A and B) Protein content of TERT in NPCs treated with HG and HG + CAG or AG-IV as tested with western blotting. $\alpha$-Tubulin was used as the loading control and for band density normalization. (C) mRNA expression levels of TERT in NPCs treated with HG and HG plus CAG and AG-IV as measured by reverse transcription-quantitative PCR with $\beta$-Actin as house-keeping gene for normalization. (D) Relative telomere length in NPCs treated with HG and HG plus CAG and AG-IV was assessed by the quantitative PCR method with 36B4 being the single copy gene for normalization. NPCs, nucleus pulposus cells. ${ }^{*} \mathrm{P}<0.05 ;{ }^{* *} \mathrm{P}<0.01$ vs. DMSO HG. CAG, Cycloastragenol; AG-IV, Astragaloside IV; HG, high glucose $(50 \mathrm{mM})$; LG, low glucose $(5.5 \mathrm{mM})$; TERT, telomerase reverse transcriptase; DLG, DMSO low glucose; DHG, DMSO high glucose.

$24 \mathrm{~h}$ and then treated with a $\mathrm{HG}$ concentration of $50 \mathrm{mM}$ for $72 \mathrm{~h}$. Fig. 7A presents the expression levels of apoptosis-related proteins (c-C3, BAX and $\mathrm{Bcl}-2)$ as detected by western blotting. Fig. 7B, C and E demonstrates that expression levels of c-C3 and BAX proteins were significantly increased, while Bcl-2 was significantly decreased in HG-only conditions 

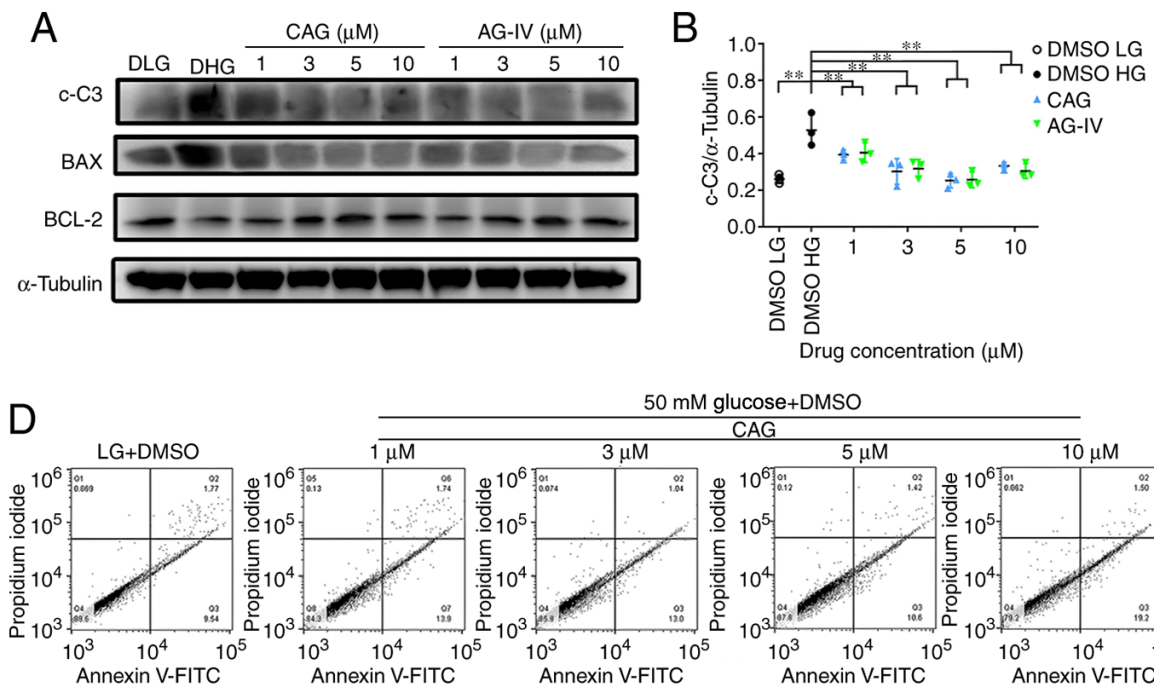

$50 \mathrm{mM}$ glucose+DMSO

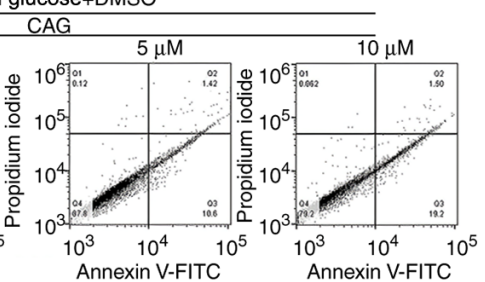

$50 \mathrm{mM}$ glucose+DMSO

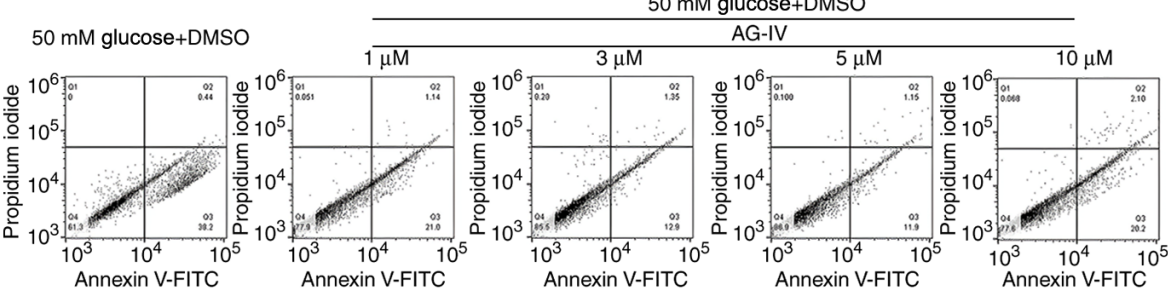

$50 \mathrm{mM}$ glucose+DMSO
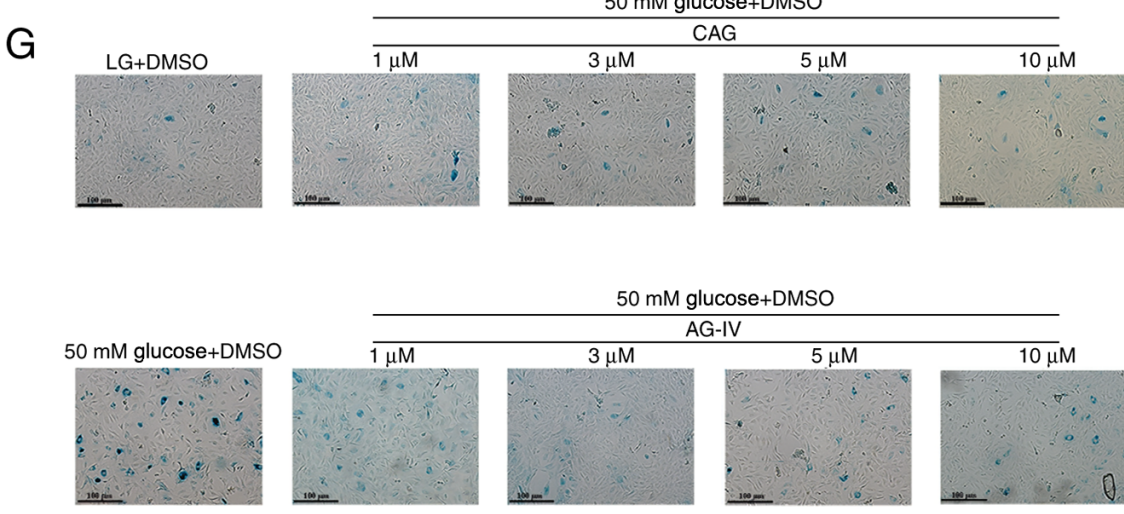

$50 \mathrm{mM}$ glucose+DMSO
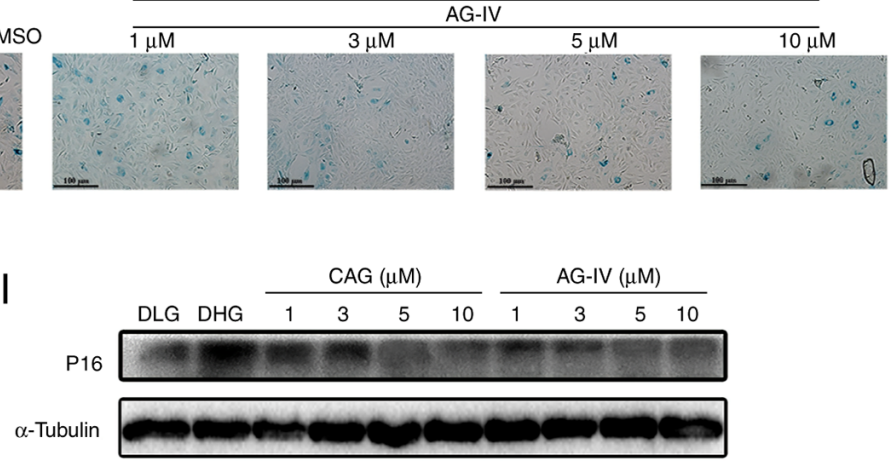
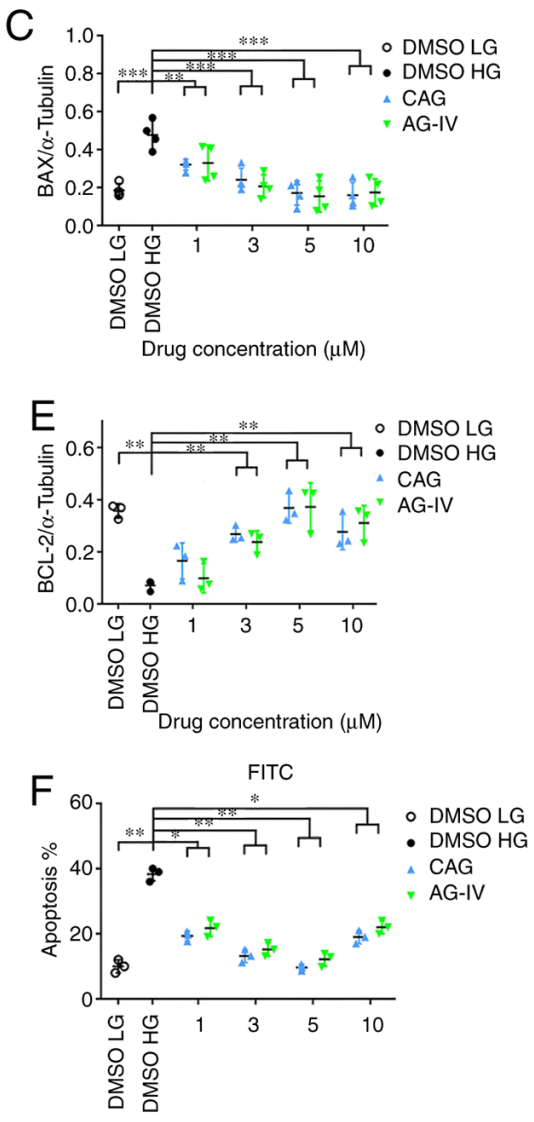

Drug concentration $(\mu \mathrm{M})$
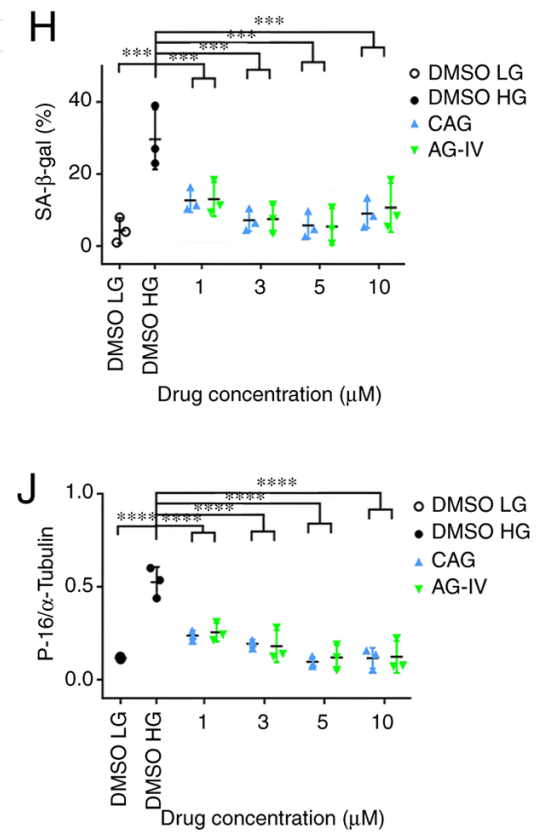

Figure 7. CAG and AG-IV treatment inhibits HG-induced NPC apoptosis and senescence. (A) Western blotting results and quantification of (B) c-C3, (C) BAX and (E) BCL-2 of NPCs treated with HG and HG plus CAG or AG-IV. (D) Apoptosis flow cytometry plots and (F) quantification of results of NPCs treated with HG and HG plus CAG or AG-IV. (G) SA- $\beta$-gal staining assay was performed and (H) quantified on NPCs pretreated with CAG or AG-IV and then with HG (magnification, x100; scale bar, $100 \mu \mathrm{m}$ ). (I) Western blotting and (J) quantification of the protein contents of p16 in NPCs treated with HG and HG plus CAG or AG-IV. ${ }^{*} \mathrm{P}<0.05 ;{ }^{* *} \mathrm{P}<0.01 ;{ }^{* * *} \mathrm{P}<0.001 ;{ }^{* * * *} \mathrm{P}<0.0001$ vs. DMSO HG. CAG, Cycloastragenol; AG-IV, Astragaloside IV; NPCs, nucleus pulposus cells; c-C3, cleaved caspase 3; HG, high glucose $(50 \mathrm{mM})$; LG, low glucose $(5.5 \mathrm{mM})$.

compared with the LG group. However, while c-C3 and BAX protein levels were significantly decreased in the drug treatment groups compared with the HG group, while Bcl-2 was significantly increased $(\mathrm{P}<0.01)$.
Meanwhile, as presented in Fig. 7D and F, the percentage of FITC (apoptosis marker) as detected by Annexin-V was significantly increased in HG conditions compared with the LG group, while the percentage decreased in 
drug-treated groups compared with the HG group $(\mathrm{P}<0.05)$. Moreover, the $\beta$-Gal staining in Fig. $7 \mathrm{G}$ and $\mathrm{H}$ shows a significantly higher percentage of stain-positive cells in the HG group compared with the LG group; whereas, the percentage of stain-positive cells significantly decreased in the drug treated groups $(\mathrm{P}<0.0001)$. Finally, as presented in Fig. 7I and $\mathrm{J}$, the expression levels of $\mathrm{p}-16$ protein were significantly increased in the HG only group compared with the LG condition group; whereas, the expression levels decreased in the drug-treated groups compared with the $\mathrm{HG}$ group $(\mathrm{P}<0.0001)$. These result demonstrated that $\mathrm{CAG}$ and AG-IV attenuated the cellular apoptosis and senescence of NPCs treated with HG, and this was most notable at concentrations of 3 or $5 \mathrm{mM}$.

\section{Discussion}

Senescence and apoptosis are considered to be the main contributors to the pathological characteristics of IVDD and Db-IVDD $(5,6,26,27)$. In senescence the cell cycle is arrested, viability is reduced and levels of catabolic cytokines and extracellular matrix-degrading enzymes are increased $(26,28)$. One of the main causes of senescence is telomere attrition, where the telomere length is shortened to an extent that no more cell division is possible. Though this can be avoided by the activation of telomerase (which can elongate telomeres). TERT the main subunit of the telomerase complex, has been indicated to significantly suppress p16 expression (a senescence-associated protein) (14). Lower expression levels of TERT have been implicated in a number of degenerative diseases, such as amyotrophic lateral sclerosis and age-related macular degeneration $(13,22)$. CAG and AG-IV, the bioactive constituents of the traditional Chinese herb Astragalus membranaceus, have been identified as small-molecule TERT activators $(16,29)$. Previous studies have demonstrated that CAG and AG-IV were able to alleviate and reverse degenerative diseases by activating telomerase $(22,29,30)$.

The present study examined the hypothesis that CAG and AG-IV may postpone the progression of HG-IVDD by upregulating TERT, without the disadvantages of activating TERT by viral transfection. The results demonstrated that CAG and AG-IV protected against HG-induced cellular senescence and apoptosis via activation of telomerase, while at the same time increasing the telomere length for prolonged survival and replications. Previous studies have indicated that CAG and/or AGIV can protect or delay senescence and apoptosis (30-32) in different conditions, and that they are telomerase activators $(29,30)$; however, to the best of our knowledge, this was the first study to examine their effect on NPCs in HG conditions or examined their association with TERT, senescence and apoptosis in HG conditions.

In diabetes, the main pathological factor is the high levels of serum glucose, which leads to complications associated with diabetes. The present study selected HG concentrations $(12.5,25,50,100$ and $200 \mathrm{mM})$ as the stimulant, as previously performed by other studies to mimic the pathophysiology of Db-IVDD in vitro $(7,33,34)$. The current study tested the effect of different concentrations of glucose on cellular viability, morphology, senescence, apoptotic markers and telomerase expression, as well as the telomere length.
Subsequently, $50 \mathrm{mM}$ was selected to represent $\mathrm{HG}$ conditions, as this had a significant effect under various treatment times.

A previous study demonstrated that $\mathrm{HG}$ concentrations can adversely affect cellular viability (35). The present study used the CCK-8 assay to evaluate cellular viability and revealed that HG concentrations adversely affected the cellular viability of NPCs in a dose-dependent manner. Whereas treatment with CAG or AG-IV improved the cellular viability, especially when treated with the concentrations of 3 or $5 \mathrm{mM}$. It was hypothesized that this may be associated with the activation of telomerase by CAG and AG-IV, which in turn protects from replicative and stress-related senescence, in addition to apoptosis of the NPCs.

It has been reported that $\mathrm{HG}$ concentrations and diabetes can cause cellular senescence in NPCs $(5,7)$. A previous study demonstrated that TERT overexpression in human NPCs can protect against cell cycle arrest by extending their replicative capacity (36). It was hypothesized that the ability of CAG (30) and AG-IV (29) to activate TERT attenuates senescence. The present study used p16 protein levels and SA- $\beta$-gal staining markers to measure cellular senescence, and it was revealed that cellular senescence increased following treatment with glucose in a dose-dependent manner in NPCs. However, by pretreating the cells with CAG or AG-IV the cellular senescence was attenuated in NPCs treated with HG, especially when at the concentrations of 3 or $5 \mathrm{mM}$.

As reported in previous studies, diabetes and HG concentrations can cause apoptosis $(5,35)$. CAG and AG-IV have been proven to have anti-apoptotic and pro-survival properties both in vitro and in vivo in different disease models, such as Parkinson's disease and cerebral ischemia-reperfusion injury (30-32). Also, as aforementioned, they are potent activators of TERT, which is reported to have a protective effect against apoptosis (36). The current study used c-C3, BAX and $\mathrm{Bcl}-2$ proteins expression levels and FITC-Annexin- $\mathrm{V}$ as markers for apoptosis. It was revealed that apoptosis was increased by glucose treatment in a dose-dependent manner in NPCs. However, by pretreating the cells with CAG or AG-IV, apoptosis was decreased in NPCs with HG conditions.

Aging degenerative cells exhibit increased telomere attrition, which is also a feature of other degenerative diseases including osteoarthritis, neurodegeneration and diabetes $(9,37,38)$. Evidence has suggested that telomerase can protect cells from telomere attrition and, thus, protects from senescence, apoptosis and inflammation $(14,39,40)$. Previous studies have demonstrated that CAG and AGIV can activate TERT, the main subunit of the telomerase complex $(29,30)$, which can elongate telomere ends, overcoming telomere attrition $(12,36,39)$. Thus, the present study studied the anti-apoptotic and anti-senescent effects of CAG and AG-IV with regards to telomerase activation and telomere lengthening. The current study revealed that at HG concentrations, TERT expression was significantly decreased at both the mRNA and protein level, and that the telomere length was shortened. This suggested that HG reduced TERT protein expression and induced telomere attrition, playing a role in IVDD. However, following CAG and AG-IV pretreatment, TERT expression and telomere length both increased in NPCs undergoing HG-induced stress. This suggested that CAG and 
AG-IV may serve a protective role against HG-induced IVDD via an increase in TERT expression and telomere lengthening.

It has been well characterized that morphological changes occur in the diabetic disc both at gross and cellular levels, and these changes are more prominent in the NP region (41). Disc degeneration results in a reduction in water content and increased breakdown of collagen type II in NP (42). In addition, the increased expression of senescence markers, such as p16 in the NP aggravate IVDD (5,37), which is also associated with the altered phenotype of having morphologically larger cell types. Furthermore, previous studies have shown that HG can adversely affect cellular proliferation and increase the expression of matrix metalloproteinases, also resulting in IVDD $(6,43)$. The present study demonstrated that CAG and AG-IV pretreatment resulted in improved morphology of the HG-treated NPCs and significantly increased their viability. By contrast, the cells treated with HG only demonstrated larger cell types with a coarse and spindled appearance.

These findings may be beneficial for future research and/or clinical trials; furthermore, they may also be used to formulate a new type of culture media. HG culture media may accelerate senescence in certain types of cells, while these drugs could be helpful in delaying that. In addition, these drugs may potentially help diabetic patients prevent the development of Db-IVDD.

There are certain limitations to the present study. Firstly, the in vitro $\mathrm{HG}$-induced Db-IVDD model does not perfectly reflect in vivo aspects of IVDD with diabetes, the reason for that was the limited budget of the present study. Thus, further in vivo studies are needed to know the effect of these drugs. Secondly, the present study did not focus on an in-depth study of the TERT pathway or mechanisms associated with senescence and apoptosis; therefore, further studies are needed to gain more in-depth knowledge of the signaling pathways involved. Thirdly, there was no investigation carried out on the effect of these drugs on oxidative stress, such as reactive oxygen species (ROS), due to the HG conditions. Further studies are needed to address this.

It is known that p53 can suppress transcription of TERT, and that this may play a role in p53-mediated apoptosis. The activation of NF- $\kappa \mathrm{B}$ induces TERT expression, which suggests the possibility that TERT is upregulated in response to survival signals that activate NF- $\mathrm{NB}$; including growth factors, cytokines and stress responses. Moreover, TERT expression is induced by the transcription factor c-Myc, a protein strongly associated with cell immortalization and cancer. All this suggests that telomerase acts to suppress an early step in the cell death pathway prior to the mitochondrial step at which Bcl-2 acts. Therefore, we hypothesize that CAG and AG-IV may inhibit p53, BAX, PUMA, Bim and ROS and, in turn, promote controlled expression of pro-survival protein pathways such as TERT, c-Myc, $\mathrm{NF}-\kappa \mathrm{B}$ and Bcl-2.

In summary, the present study revealed that CAG and AG-IV serve a notable role in the prevention of HG-mediated IVDD by attenuating senescence, including replicative senescence and stress-induced premature senescence. These drugs may also inhibit apoptosis in NPCs by upregulating telomerase activation and lengthening the telomere. TERT may represent a potential target for future therapeutic interventions, while CAG and AG-IV could be potential therapeutic agents in attenuating HG-IVDD.

\section{Acknowledgments}

Not applicable.

\section{Funding}

The present study is supported by grants from National Regional Natural Fund of China (grant no. 81660366), Zhejiang Provincial Natural Science Foundation of China (grantno.LY18H060012andLY17H060010),ZhejiangProvincial Key Laboratory of Orthopedics (grant no. ZJGK1802Z), Zhejiang Public Service Technology Research Program/Social Development (grant no. LGF18H060008), Major Scientific And Technological Project of Medical and Health in Zhejiang Province (grant no. WKJ-ZJ-1527), Zhejiang Provincial Project for Medical and Health Science and Technology (grant no. 2017KY463) and Wenzhou Science and Technology Bureau Foundation (grant no. Y20170092).

\section{Availability of data and materials}

The datasets used and/or analyzed during the current study are available from the corresponding author on reasonable request.

\section{Authors' contributions}

$\mathrm{HH}$ and JX performed the research, analyzed the data and prepared the manuscript. QG assisted in western blotting and $\beta$-gal staining. JD assisted in cell culture. ZJ collected nucleus pulposus from rats. SL provided technical assistance in flow cytometry. HZ performed statistical analysis. XW and XZ designed the research and supervised the process of the study. $\mathrm{HH}$ and JX confirm the authenticity of all the raw data. All authors have read and approved the final manuscript.

\section{Ethics approval and consent to participate}

The present study was approved by the Ethics Committee of Wenzhou Medical University (approval no. wydw2014-0129; Wenzhou, China).

\section{Patient consent for publication}

Not applicable.

\section{Competing interests}

The authors declare that they have no competing interest.

\section{References}

1. Deyo RA and Mirza SK: CLINICAL PRACTICE. Herniated lumbar intervertebral disk. N Engl J Med 374: 1763-1772, 2016.

2. Modic MT and Ross JS: Lumbar degenerative disk disease. Radiology 245: 43-61, 2007.

3. Kadow T, Sowa G, Vo N and Kang JD: Molecular basis of intervertebral disc degeneration and herniations: What are the important translational questions. Clin Orthop Relat Res 473: 1903-1912, 2015

4. Jiang L, Zhang X, Zheng X, Ru A, Ni X, Wu Y, Tian N, Huang Y, Xue E, Wang $\mathrm{X}$ and $\mathrm{Xu} \mathrm{H}$ : Apoptosis, senescence, and autophagy in rat nucleus pulposus cells: Implications for diabetic intervertebral disc degeneration. J Orthop Res 31: 692-702, 2013. 
5. Wang L, Gao P, Zhang M, Huang Z, Zhang D, Deng Q,Li Y, Zhao Z, Qin X, Jin D, et al: Prevalence and ethnic pattern of diabetes and prediabetes in China in 2013. JAMA 317: 2515-2523, 2017.

6. Won HY, Park JB, Park EY and Riew KD: Effect of hyperglycemia on apoptosis of notochordal cells and intervertebral disc degeneration in diabetic rats. J Neurosurg Spine 11: 741-748, 2009.

7. Kong JG, Park JB, Lee D and Park EY: Effect of high glucose on stress-induced senescence of nucleus pulposus cells of adult rats. Asian Spine J 9: 155-161, 2015.

8. Zhang XU, Yang MK, Li Z, Liu C, Wu JS and Wang J: Expression and significance of telomerase in the nucleus pulposus tissues of degenerative lumbar discs. Biomed Rep 3: 813-817, 2015.

9. Monickaraj F, Aravind S, Gokulakrishnan K, Sathishkumar C Prabu P, Prabu D, Mohan V and Balasubramanyam M: Accelerated aging as evidenced by increased telomere shortening and mitochondrial DNA depletion in patients with type 2 diabetes. Mol Cell Biochem 365: 343-350, 2012.

10. Xiao F, Zheng X, Cui M, Shi G, Chen X, Li R, Song Z, Rudolph KL, Chen B and Ju Z: Telomere dysfunction-related serological markers are associated with type 2 diabetes. Diabetes Care 34: 2273-2278, 2011.

11. Skvortsov DA, Zvereva ME, Shpanchenko OV and Dontsova OA: Assays for detection of telomerase activity. Acta Naturae 3: 48-68, 2011.

12. Chung SA, Wei AQ, Connor DE, Webb GC, Molloy T, Pajic M and Diwan AD: Nucleus pulposus cellular longevity by telomerase gene therapy. Spine (Phila Pa 1976) 32: 1188-1196, 2007.

13. Eitan E, Tichon A, Gazit A, Gitler D, Slavin S and Priel E: Novel telomerase-increasing compound in mouse brain delays the onse of amyotrophic lateral sclerosis. EMBO Mol Med 4: 313-329, 2012.

14. Graham MK, Principessa L, Antony L, Meeker AK and Isaacs JT Low p16(INK4a) expression in early passage human prostate basal epithelial cells enables immortalization by telomerase expression alone. Prostate 77: 374-384, 2017.

15. Yu Y, Zhou L, Yang Y and Liu Y: Cycloastragenol: An exciting novel candidate for age-associated diseases. Exp Ther Med 16: 2175-2182, 2018.

16. Szabo NJ: Dietary safety of cycloastragenol from Astragalus spp.: Subchronic toxicity and genotoxicity studies. Food Chem Toxicol 64: 322-334, 2014

17. Xiao WL, Motley TJ, Unachukwu UJ, Lau CB, Jiang B, Hong F, Leung PC, Wang QF, Livingston PO, Cassileth BR and Kennelly EJ: Chemical and genetic assessment of variability in commercial Radix Astragali (Astragalus spp.) by ion trap LC-MS and nuclear ribosomal DNA barcoding sequence analyses. J Agric Food Chem 59: 1548-1556, 2011.

18. Zhang N, Wang XH, Mao SL and Zhao F: Astragaloside IV improves metabolic syndrome and endothelium dysfunction in fructose-fed rats. Molecules 16: 3896-3907, 2011

19. Wang B and Chen MZ: Astragaloside IV possesses antiarthritic effect by preventing interleukin 1beta-induced joint inflammation and cartilage damage. Arch Pharm Res 37: 793-802, 2014.

20. Wang L, Gu W, Shi Y, Chen Y and Tan Y: Protective effects of astragaloside IV on IL-8-treated diaphragmatic muscle cells. Exp Ther Med 17: 519-524, 2019.

21. Wang $\mathrm{J}$ and Guo HM: Astragaloside IV ameliorates high glucose-induced HK-2 cell apoptosis and oxidative stress by regulating the Nrf2/ARE signaling pathway. Exp Ther Med 17: 4409-4416, 2019

22. Dow CT and Harley CB: Evaluation of an oral telomerase activator for early age-related macular degeneration-a pilot study. Clin Ophthalmol 10: 243-249,2016.

23. Zheng G, Pan Z, Zhan Y, Tang Q, Zheng F, Zhou Y, Wu Y, Zhou Y, Chen D, Chen J, et al: TFEB protects nucleus pulposus cells against apoptosis and senescence via restoring autophagic flux. Osteoarthritis Cartilage 27: 347-357, 2019.

24. Livak KJ and Schmittgen TD: Analysis of relative gene expression data using real-time quantitative PCR and the 2(-Delta Delta C(T)) method. Methods 25: 402-408, 2001.

25. Cawthon RM: Telomere measurement by quantitative PCR. Nucleic Acids Res 30: e47, 2002.

26. Chen J, Xie JJ, Jin MY, Gu YT, Wu CC, Guo WJ, Yan YZ, Zhang ZJ, Wang JL, Zhang XL, et al: Sirt6 overexpression suppresses senescence and apoptosis of nucleus pulposus cells by inducing autophagy in a model of intervertebral disc degeneration. Cell Death Dis 9: 56, 2018.

27. Kletsas D: Senescent cells in the intervertebral disc: Numbers and mechanisms. Spine J 9: 677-678, 2009.
28. Davalos AR, Coppe JP, Campisi J and Desprez PY: Senescent cells as a source of inflammatory factors for tumor progression. Cancer Metastasis Rev 29: 273-283, 2010

29. Yung LY, Lam WS, Ho MK, Hu Y, Ip FC, Pang H, Chin AC, Harley CB, Ip NY and Wong YH: Astragaloside IV and cycloastragenol stimulate the phosphorylation of extracellular signal-regulated protein kinase in multiple cell types. Planta Med 78: $115-121,2012$

30. Ip FC, Ng YP, An HJ, Dai Y, Pang HH, Hu YQ, Chin AC, Harley CB, Wong YH and Ip NY: Cycloastragenol is a potent telomerase activator in neuronal cells: Implications for depression management. Neurosignals 22: 52-63, 2014.

31. Huang XP, Tan H, Chen BY and Deng CQ: Combination of total Astragalus extract and total Panax notoginseng saponins strengthened the protective effects on brain damage through improving energy metabolism and inhibiting apoptosis after cerebral ischemia-reperfusion in mice. Chin J Integr Med 23: 445-452, 2017

32. Zhang ZG, Wu L, Wang JL, Yang JD, Zhang J, Zhang J, Li LH, Xia Y, Yao LB, Qin HZ and Gao GD: Astragaloside IV prevents MPP(+)-induced SH-SY5Y cell death via the inhibition of Bax-mediated pathways and ROS production. Mol Cell Biochem 364: 209-216, 2012.

33. Jiang C, Liu S, Cao Y and Shan H: High glucose induces autophagy through PPAR $\gamma$-dependent pathway in human nucleus pulposus cells. PPAR Res 2018: 8512745, 2018.

34. Cheng X, Ni B, Zhang F, Hu Y and Zhao J: High glucose-induced oxidative stress mediates apoptosis and extracellular matrix metabolic imbalances possibly via p38 MAPK activation in rat nucleus pulposus cells. J Diabetes Res 2016: 3765173, 2016.

35. Zhou KL, Zhou YF, Wu K, Tian NF, Wu YS, Wang YL, Chen DH, Zhou B, Wang XY, Xu HZ and Zhang XL: Stimulation of autophagy promotes functional recovery in diabetic rats with spinal cord injury. Sci Rep 5: 17130, 2015.

36. Liang W, Ye D, Dai L, Shen Y and Xu J: Overexpression of hTERT extends replicative capacity of human nucleus pulposus cells, and protects against serum starvation-induced apoptosis and cell cycle arrest. J Cell Biochem 113: 2112-2121, 2012.

37. Le Maitre CL, Freemont AJ and Hoyland JA: Accelerated cellular senescence in degenerate intervertebral discs: A possible role in the pathogenesis of intervertebral disc degeneration. Arthritis Res Ther 9: R45, 2007.

38. Baltzis D, Meimeti E, Grammatikopoulou MG, Roustit M, Mavrogonatou E, Kletsas D, Efraimidou S, Manes C, Nikolouzakis TK, Tsiaoussis J, et al: Assessment of telomerase activity in leukocytes of type 2 diabetes mellitus patients having or not foot ulcer: Possible correlation with other clinical parameters. Exp Ther Med 15: 3420-3424, 2018.

39. Wu J, Wang D, Ruan D, He Q, Zhang Y, Wang C, Xin H, Xu C and Liu Y: Prolonged expansion of human nucleus pulposus cells expressing human telomerase reverse transcriptase mediated by lentiviral vector. J Orthop Res 32: 159-166, 2014.

40. Wu J, Wang D, Zhang C, Wang C, Zhang Y, Xin H, He Q and Ruan D: Extending the activities of human nucleus pulposus cells with recombinant adeno-associated virus vector-mediated human telomerase reverse transcriptase gene transfer. Tissue Eng Part A 17: 2407-2415, 2011.

41. Illien-Junger S, Grosjean F, Laudier DM, Vlassara H, Striker GE and Iatridis JC: Combined anti-inflammatory and anti-AGE drug treatments have a protective effect on intervertebral discs in mice with diabetes. PLoS One 8: e64302, 2013.

42. Antoniou J, Steffen T, Nelson F, Winterbottom N, Hollander AP, Poole RA, Aebi M and Alini M: The human lumbar intervertebral disc: Evidence for changes in the biosynthesis and denaturation of the extracellular matrix with growth, maturation, ageing, and degeneration. J Clin Invest 98: 996-1003, 1996.

43. Park EY and Park JB: Dose- and time-dependent effect of high glucose concentration on viability of notochordal cells and expression of matrix degrading and fibrotic enzymes. Int Orthop 37: 1179-1186, 2013.

This work is licensed under a Creative Commons Attribution-NonCommercial-NoDerivatives 4.0 International (CC BY-NC-ND 4.0) License. 